\title{
ESPAÇAMENTOS DE PLANTIO NO RENDIMENTO DE ÓLEO ESSENCIAL E CRESCIMENTO DE MANJERICÃO
}

\author{
Luiz Henrique Tutida Yokota ${ }^{1}$, Jose Roberto Pinto de Souza ${ }^{2}$
}

\footnotetext{
${ }^{1}$ Doutorando em Agronomia na Universidade Estadual de Londrina (PR). E-mail: luiztutida@gmail.com

${ }^{2}$ Professor Doutor do Departamento de Agronomia na Universidade Estadual de Londrina (PR).
}

RESUMO: O manjericão produz óleo essencial valorizado no mercado internacional, sendo o Brasil um dos maiores produtores mundiais. O espaçamento é um dos fatores que mais influenciam o crescimento e o rendimento final de cultivo. O objetivo do trabalho foi avaliar espaçamentos entre plantas e entre linhas no rendimento de óleo essencial e crescimento de manjericão. $\mathrm{O}$ experimento foi realizado em Londrina-PR, no período de fevereiro a maio de 2011, em delineamento experimental de blocos casualizados com três tratamentos e 10 repetições. Os espaçamentos entre plantas e entre linhas utilizados foram de 0,20 x $0,20 \mathrm{~m}$, $0,30 \times 0,30 \mathrm{~m}$ e $0,40 \times 0,40 \mathrm{~m}$. O corte ocorreu no início do florescimento, a altura do oitavo nó, aos 40 dias após o transplantio. As variáveis avaliadas foram: a altura da planta, área foliar, massa seca da parte aérea, produtividade de massa seca da parte aérea e rendimento de óleo essencial. Nas condições em que o experimento foi conduzido, o adensamento de plantas foi capaz de promover maior altura das plantas, produtividade de massa seca da parte aérea e rendimento de óleo essencial de manjericão.

Palavras-chave: Ocimum basilicum L. Biomassa. Competição intraespecífica.

\section{PLANTING SPACES IN ESSENTIAL OIL YIELD AND BASIL GROWTH}

\begin{abstract}
The basil produces essential oil valued in the international market, Brazil being one of the largest producers in the world. Spacing is one of the factors that most influence growth and final crop yield. The objective was to evaluate spacing between plants and between rows in essential oil yield and basil growth. The experiment was conducted in Londrina-PR, from February to May 2011, in a randomized block design with three treatments and 10 replications. The spacing between plants and between rows used were $0.20 \times 0.20 \mathrm{~m}, 0.30 \times 0.30 \mathrm{~m}$ and $0.40 \times 0.40 \mathrm{~m}$. The cut occurred at flowering, at the height of the eighth node, 40 days after transplanting. The evaluated variables were: plant height, leaf area, shoot dry mass, dry shoot mass yield and essential oil yield. Under the conditions under which the experiment was conducted, plant densification was able to promote higher plant height, dry shoot mass yield and basil essential oil yield.
\end{abstract}

Key words: Ocimum basilicum L. Biomass. Intraspecific competition. 


\section{INTRODUÇÃO}

O manjericão (Ocimum basilicum L.), pertencente à família Lamiaceae, é um subarbusto aromático, ereto, muito ramificado, de folhas simples e flores brancas que foi introduzido no Brasil pela colônia italiana (LORENZI; MATOS, 2008). É cultivado por pequenos produtores para a comercialização das folhas (SILVA et al., 2012).

A espécie produz óleo essencial valorizado no mercado internacional com alta concentração de linalol, sendo utilizado nas indústrias de condimentos e cosméticos (CARVALHO FILHO et al., 2006).

O Brasil é um dos maiores produtores mundiais de óleo essencial, porém enfrenta problemas como os baixos investimentos do governo no setor e a falta de manutenção no padrão de qualidade dos óleos (BIZZO et al., 2009). Diante dessas adversidades, é importante avaliar o desempenho de plantas condimentares perante práticas agronômicas como o espaçamento.

O espaçamento é um dos fatores que mais influenciam o crescimento e o rendimento final de cultivo por modificar a capacidade fotossintética das plantas, além de contribuir de forma positiva ou negativa na competição entre a cultura e plantas invasoras por água, nutrientes e radiação (MONTEIRO et al., 2011).

Assim, o objetivo do trabalho foi avaliar os espaçamentos entre plantas e entre linhas no rendimento de óleo essencial e crescimento de manjericão.

\section{MATERIAL E MÉTODOS}

$\mathrm{O}$ experimento foi realizado em Londrina-PR $\left(23^{\circ} 23^{\prime} \mathrm{S}\right.$ e $51^{\circ} 11^{\prime} \mathrm{W} ; 566 \mathrm{~m}$ de altitude), no período de fevereiro/2011 a maio/2011. O clima é Cfa, segundo a classificação de Köppen e a precipitação média anual é de $1615 \mathrm{~mm}$. O solo da área experimental é classificado como Latossolo Vermelho Distroférrico (EMBRAPA, 2013) e apresentou a seguinte análise química na camada de $0-0,20 \mathrm{~m}$ (Tabela 1):

Tabela 1. Caracterização química do solo da área experimental para o cultivo de manjericão.

\begin{tabular}{|c|c|c|c|c|c|c|}
\hline \multirow{2}{*}{$\begin{array}{c}\mathrm{pH} \\
\mathrm{CaCl}_{2}\end{array}$} & P disponível & $\mathrm{Ca}^{+2}$ & $\mathrm{Mg}^{+2}$ & $\mathrm{~K}^{+}$ & $\begin{array}{c}\text { CTC } \\
\text { Efetiva }\end{array}$ & V \\
\hline & $\left(\mathrm{mg} \cdot \mathrm{dm}^{-3}\right)$ & \multicolumn{4}{|c|}{$\left(\mathrm{cmol}_{\mathrm{c}} \cdot \mathrm{dm}^{-3}\right)$} & $(\%)$ \\
\hline 5,54 & 28,75 & 8,55 & 2,61 & 0,52 & 11,68 & 75,32 \\
\hline
\end{tabular}

A produção das mudas de manjericão, cultivar Basilicão, ocorreu em estufa coberta com malha termo refletora Aluminet Externa para retenção de $50 \%$ do fluxo de radiação solar. A semeadura foi efetuada em tubetes de $50 \mathrm{~cm}^{3}$ que foram preenchidos com mistura contendo $25 \%$ de casca de arroz carbonizada e $75 \%$ de vermicomposto. Estes recipientes foram sustentados por bandejas com capacidade para 176 tubetes e ficaram suspensas em 
estrutura metálica a 1,0 m do solo. O desbaste foi realizado após a formação do $2^{\circ}$ par de folhas, deixando uma plântula por célula.

O preparo da área experimental ocorreu com enxada rotativa. Não foi necessário realizar adubações no solo (Tabela 1). O controle de formigas do gênero Acromyrmex (quenquém) foi efetuado antes da instalação das plântulas, com formicidas à base de fipronil. As mudas de manjericão foram transplantadas à campo 45 dias após a semeadura, conforme o arranjo de cada tratamento. As irrigações eram realizadas diariamente nas primeiras horas da manhã com aspersores. O controle de plantas daninhas foi efetuado através de capinas manuais.

O delineamento experimental empregado foi o de blocos casualizados com três tratamentos e 10 repetições. Os espaçamentos entre plantas e entre linhas utilizados foram de $0,20 \times 0,20 \mathrm{~m}, 0,30 \times 0,30 \mathrm{~m}$ e $0,40 \times 0,40 \mathrm{~m}$. Cada parcela foi composta por seis linhas de plantio, sendo que a área útil amostrada foi representada pelas quatro linhas centrais.

A colheita foi realizada cortando-se a parte aérea das plantas, no início do florescimento, a altura do oitavo nó aos 40 dias após o transplantio (DAT).

As variáveis avaliadas foram: a altura da planta, área foliar, massa seca da parte aérea, produtividade de massa seca da parte aérea e rendimento de óleo essencial. A altura foi obtida com o auxílio de régua milimetrada, medida a partir da base até o ápice da planta. A área foliar foi determinada por régua medindo o maior comprimento versus a maior largura da folha. As plantas coletadas foram acondicionadas em sacos de papel identificados e colocados em estufa com circulação forçada de ar a $40{ }^{\circ} \mathrm{C}$. Após atingirem massa constante por pesagem em balança de precisão foram obtidas a massa seca da parte aérea e a produtividade de massa seca da parte aérea. O óleo essencial de manjericão foi obtido através do método de arraste a vapor (KOKETSU; GONÇALVES, 1991). Para a extração do óleo essencial foram utilizadas amostras de 100 gramas de folhas secas/parcela e colocadas no Mini Destilador D1 da LINAX®. Cada extração foi realizada por um período de 90 minutos. Ao final, foi calculado o rendimento de óleo essencial em $\mathrm{L} \mathrm{ha}^{-1}$.

Os dados coletados foram submetidos à análise de variância e a comparação entre as médias foi efetuada pelo teste de Tukey a $5 \%$ de probabilidade. Foi utilizado o programa Sisvar® versão 5.3 para as análises estatísticas (FERREIRA, 2011).

\section{RESULTADOS E DISCUSSÃO}

A altura das plantas foi influenciada pelos diferentes espaçamentos, sendo que os tratamentos de 0,20 x 0,20 m e 0,30 x 0,30 m proporcionaram as plantas mais altas (Tabela 2). Blank et al. (2007) verificaram também que a densidade de plantio influenciou a altura das plantas de Cymbopogon citratus. Yokota et al. (2015) observaram, aos 40 DAT, altura das plantas de 57,65 cm após utilizarem espaçamento entre plantas de $30 \mathrm{~cm}$ e entre linhas

Cultura Agronômica, Ilha Solteira, v.26, n.4, p.514-519, 2017 
de $30 \mathrm{~cm}$. De acordo com Monteiro et al. (2011), a maior altura das plantas em menores espaçamentos de plantio pode estar associado à competição por luz.

Tabela 2. Altura das plantas de manjericão sob diferentes espaçamentos entre plantas e entre linhas.

\begin{tabular}{cc}
\hline Espaçamentos $(\mathrm{m})$ & Altura $(\mathrm{cm})$ \\
\hline $0,20 \times 0,20$ & $54,88 \mathrm{a}^{*}$ \\
$0,30 \times 0,30$ & $55,03 \mathrm{a}$ \\
$0,40 \times 0,40$ & $47,55 \mathrm{~b}$ \\
\hline C.V. $(\%)$ & 3,79
\end{tabular}

*Médias seguidas da mesma letra minúscula na coluna não diferem estatisticamente pelo teste de Tukey $(\mathrm{p}<0,05 \%)$.

A área foliar não foi influenciada pelos espaçamentos entre plantas e entre linhas (Tabela 3). De acordo com Dechen e Nachtigall (2007), a disponibilidade de nutrientes como o nitrogênio é capaz de promover o crescimento das folhas, logo, o adensamento das plantas de manjericão não promoveu competição por nutrientes. Em relação a massa seca da parte aérea foram verificados resultados semelhantes aos da área foliar (Tabela 3). A massa seca de um cultivo é obtida da transformação da energia solar em energia química, sendo que a interceptação da luz do sol é realizada, principalmente, pelas folhas das plantas, aumentando ou diminuindo segundo a área foliar (SHIBLES; WEBER, 1966).

Tabela 3. Área foliar e massa seca da parte aérea de plantas de manjericão sob diferentes espaçamentos entre plantas e entre linhas.

\begin{tabular}{ccc}
\hline Espaçamentos $(\mathrm{m})$ & Área foliar $\left(\mathrm{cm}^{2}\right)$ & $\begin{array}{c}\text { Massa seca da parte aérea } \\
(\mathrm{g} / \text { planta })\end{array}$ \\
\hline $0,20 \times 0,20$ & $30,70 \mathrm{a}^{*}$ & $4,85 \mathrm{a}$ \\
$0,30 \times 0,30$ & $30,53 \mathrm{a}$ & $7,97 \mathrm{a}$ \\
$0,40 \times 0,40$ & $30,42 \mathrm{a}$ & $6,24 \mathrm{a}$ \\
\hline C.V. $(\%)$ & 3,53 & 25,55 \\
\hline
\end{tabular}

*Médias seguidas da mesma letra minúscula na coluna não diferem estatisticamente pelo teste de Tukey $(\mathrm{p}<0,05 \%)$.

Em relação à produtividade de massa seca da parte aérea foram verificados acréscimos significativos quando as plantas de manjericão foram submetidas aos arranjos de 0,20 x 0,20 m e 0,30 x 0,30 m (Tabela 4). Segundo Favorito et al. (2011), mesmo que ocorra maior pressão de competição, o maior número de plantas por área gera um acúmulo favorável à produtividade. Marco et al. (2006), após avaliarem os efeitos do espaçamento, épocas e alturas de corte no capim citronela, constataram que o plantio mais adensado proporcionou maiores ganhos de biomassa para a cultura.

$\mathrm{O}$ aumento da densidade de plantio proporcionou maior rendimento de óleo essencial (Tabela 4). Os espaçamentos de 0,20 x 0,20 m e 0,30 x 0,30 m geraram acréscimo de $148,54 \%$ e 126,90\%, respectivamente, em relação às plantas sob 0,40 x 0,40 m. Marco et al. (2007), ao trabalharem com plantas de Cymbopogon winterianum Jowitt, observaram maior 
produção de óleo essencial em menor espaçamento e maior altura de corte. Melo et al. (2011) verificaram que os menores espaçamentos apresentaram produções de óleo essencial estatisticamente superiores em plantas de alecrim-pimenta.

Tabela 4. Produtividade de massa seca da parte aérea e rendimento de óleo essencial de plantas de manjericão sob diferentes espaçamentos entre plantas e entre linhas.

\begin{tabular}{ccc}
\hline Espaçamentos $(\mathrm{m})$ & $\begin{array}{c}\text { Produtividade de massa seca } \\
\text { da parte aérea }\left(\mathrm{kg}^{*} \mathrm{ha}^{-1}\right)\end{array}$ & $\begin{array}{c}\text { Rendimento de óleo } \\
\text { essencial }\left({\left.\mathrm{L} . \mathrm{ha}^{-1}\right)}^{-1}\right.\end{array}$ \\
\hline $0,20 \times 0,20$ & $1212,93 \mathrm{a}^{*}$ & $4,25 \mathrm{a}$ \\
$0,30 \times 0,30$ & $1108,06 \mathrm{a}$ & $3,88 \mathrm{a}$ \\
$0,40 \times 0,40$ & $488,90 \mathrm{~b}$ & $1,71 \mathrm{~b}$ \\
\hline C.V. $(\%)$ & 8,31 & 8,26 \\
\hline
\end{tabular}

*Médias seguidas da mesma letra minúscula na coluna não diferem estatisticamente pelo teste de Tukey $(\mathrm{p}<0,05 \%)$.

Os resultados obtidos mostraram que o adensamento de plantas pode contribuir para aumentos na produção de manjericão. Os espaçamentos de $0,20 \times 0,20 \mathrm{~m}$ e $0,30 \times 0,30 \mathrm{~m}$ foram estatisticamente iguais nas variáveis produtividade de massa seca da parte aérea e rendimento de óleo essencial (Tabela 4). Assim, em cultivos comerciais, a utilização de 0,30 x $0,30 \mathrm{~m}$ pode repercutir em maior economia (mudas) e renda para o produtor rural.

\section{CONCLUSÃO}

O menor espaçamento entre plantas proporcionou maior produtividade de massa seca da parte aérea e rendimento de óleo essencial das plantas de manjericão.

\section{REFERÊNCIAS BIBLIOGRÁFICAS}

BIZZO, H. R.; HOVELL, A. M. C.; REZENDE, C. M. Óleos essenciais no Brasil: aspectos gerais, desenvolvimento e perspectivas. Química Nova, São Paulo, v. 32, n. 3, p.588-594, 2009.

BLANK, A. F.; ARRIGONI-BLANK, M. F.; AMANCIO, V. F.; MENDONÇA, M. C.; SANTANA FILHO, L. G. M. Densidades de plantio e doses de biofertilizante na produção de capim-limão. Horticultura Brasileira, Brasília, v. 25, n. 3, p.343-349, 2007.

CARVALHO FILHO, J. L. S.; BLANK, A. F.; ALVES, P. B.; EHLERT, P. A. D.; MELO, A. S.; CAVALCANTI, S. C. H.; ARRIGONI-BLANK, M. F.; SILVA-MANN, R. Influence of the harvesting time, temperature and drying period on basil (Ocimum basilicum L.) essential oil. Revista Brasileira de Farmacognosia, Curitiba, v. 16, n. 1, p.24-30, 2006.

DECHEN, A. R.; NACHTIGALL, G. R. Elementos requeridos à nutrição de plantas. In: NOVAIS, R. F.; V, V. H. A.; BARROS, N. F.; FONTES, R. L.; CANTARUTTI, R. B.; NEVES, J. C. L. Fertilidade do solo. Viçosa: Sociedade Brasileira de Ciência do Solo, 2007. cap. 3, p.91-132.

Cultura Agronômica, Ilha Solteira, v.26, n.4, p.514-519, 2017 
EMBRAPA Sistema Brasileiro de Classificação de Solos. 3. ed. Brasília: EMBRAPA, 2013. 353 p.

FAVORITO, P. A.; ECHER, M. M.; OFFEMANN, L. C.; SCHLINDWEIN, M. D.; COLOMBARE; L. F.; SCHINEIDER, R. P.; HACHMANN, T. L. Características produtivas do manjericão (Ocimum basilicum L.) em função do espaçamento entre plantas e entre linhas. Revista Brasileira de Plantas Medicinais, Botucatu, v. 13, especial, p.582586, 2011.

FERREIRA, D. F. Sisvar: a computer statistical analysis system. Ciência e Agrotecnologia, Lavras, v. 35, n. 6, p.1039-1042, 2011.

KOKETSU, M.; GONÇALVES, S. L. Óleos essenciais e sua extração por arraste a vapor. Rio de Janeiro: EMBRAPA-CTAA, 1991. 24 p.

LORENZI, H.; MATOS, F. J. A. Plantas medicinais no Brasil: nativas e exóticas. 2. ed. São Paulo: NOVA ODESSA, 2008. 544 p.

MARCO, C. A.; INNECCO, R.; MATTOS, S. H.; BORGES, N.S.S.; MEDEIROS FILHO, $\mathrm{S}$. Influência de espaçamento, altura e época de corte no rendimento da biomassa e óleo essencial na cultura de capim citronela (Cymbopogon winterianus Jowitt.). Revista Ciência Agronômica, Fortaleza, v. 37, n. 1, p.32-36, 2006.

MARCO, C. A.; INNECCO, R.; MATTOS, S. H.; BORGES, N. S. S.; NAGAO, E. O. Características do óleo essencial de capim-citronela em função de espaçamento, altura e época de corte. Horticultura Brasileira, Brasília, v. 25, n. 3, p.429-432, 2007.

MELO, M. T. P.; CARVALHO JÚNIOR, W. G. O.; SOUZA, M. F.; FIGUEIREDO, L. S.; MARTINS, E. R. Produção de fitomassa e teor de óleo essencial de folhas de alecrimpimenta (Lippia sidoides Cham.) em diferentes espaçamentos de plantio. Revista Brasileira de Plantas Medicinais, Botucatu, v. 13, n. 2, p.230-234, 2011.

MONTEIRO, R.; DESCHAMPS, C.; BIASI, L. A.; BIZZO, H. Desenvolvimento vegetativo de Mentha campestris Schur e produção de mentol em diferentes espaçamentos de plantio e épocas de colheita. Revista Brasileira de Plantas Medicinais, Botucatu, v. 13, n. 4, p.401407, 2011.

SHIBLES, R. M.; WEBER, C. R. Interception of solar radiation and dry matter production by various soybeam planting patterns. Crop Science, Madison, v. 6, n. 1, p.55-59, 1966.

SILVA, I. M.; GUSMÃO, S. A. L.; BARROS, A. C. A.; GOMES, R. F.; SILVA, J. P.; PEREIRA, J. K. B. Enraizamento de manjericão em diferentes substratos e doses de cinzas. Revista Brasileira de Plantas Medicinais, Botucatu, v. 14, especial, p.188-191, 2012.

YOKOTA, L. H. T.; IOSSAQUI, C. G.; HOSHINO, E. A.; SOUZA, J. R. P. Adubação foliar no desenvolvimento e produção de óleo essencial de manjericão. Revista Brasileira de Plantas Medicinais, Campinas, v. 17, n. 4, supl. II, p. 975-979, 2015.

Cultura Agronômica, Ilha Solteira, v.26, n.4, p.514-519, 2017 